\title{
Study of maternal and fetal outcomes in patients with gestational diabetes mellitus
}

\author{
Smruti Gedam¹, Sanjay Ponde ${ }^{2 *}$
}

\begin{abstract}
${ }^{1}$ Department of Obstetrics and Gynecology, Government Medical College and Hospital, Nagpur, Maharashtra, India ${ }^{2}$ Department of Obstetrics and Gynecology, Dr. D. Y. Patil Medical College, Hospital and Research Centre, Pune, Maharashtra, India
\end{abstract}

Received: 09 January 2019

Accepted: 05 February 2019

\author{
*Correspondence: \\ Dr. Sanjay Ponde, \\ E-mail: drsanjayponde@ rediffmail.com
}

Copyright: () the author(s), publisher and licensee Medip Academy. This is an open-access article distributed under the terms of the Creative Commons Attribution Non-Commercial License, which permits unrestricted non-commercial use, distribution, and reproduction in any medium, provided the original work is properly cited.

\section{ABSTRACT}

Background: Diabetes mellitus is the commonest medical problem complicating pregnancy, with possibility of grave consequences. With the present study, incidence, management and perinatal outcomes in the cases of GDM were studied.

Methods: All the pregnant patients attending antenatal clinic at the study centre during study period of three years were studied. Those with positive history were screened for GDM as early as possible and rest screened at 24-28 weeks gestation. Carpenter and Coustan criteria were used for the diagnosis of gestational diabetes mellitus. All the diagnosed cases of gestational diabetes mellitus were followed up throughout the course of gestation and complications, if any, recorded.

Results: A total of 39 patients were diagnosed as GDM. Majority were multigravida $(69.3 \%, 27)$ and weighed over $75 \mathrm{~kg}(56 \%, 22)$. Patients were mostly diagnosed at the gestational age of 31-35 weeks (n-15) and 21-25 weeks (n11). Fifteen patients $(38.4 \%)$ had HbAlc values between $6-7 \%, 14$ patients $(35.8 \%)$ between $7-8 \%$ and 3 patients had HBA1c levels more than $10 \%$. Twenty-three percent (9) patients had PIH, 13\% (5) polyhydramnios and 7.6\% (3) had PROM. Three mothers had babies suffering from IUGR. Sixteen (41\%) had full term normal delivery while $2(5.1 \%)$ patients had preterm labor and delivered normally. Twenty-one mothers (53.84\%) had LSCS, out of which 3 had preterm LSCS.

Conclusions: Diabetes during pregnancy is associated with risk factors as well as high maternal and foetal morbidity. GDM has good maternal and foetal outcomes depending upon how well the blood sugar levels are controlled.

Keywords: Gestational diabetes mellitus, Maternal and foetal outcomes

\section{INTRODUCTION}

Diabetes mellitus is one of the oldest diseases known to mankind and is counted amongst the largest global health emergencies of 21 st century. Globally, an estimated 422 million adults were living with diabetes in 2014, compared to 108 million in $1980 .^{1}$ India is home to around 69 million diabetics; which is estimated to go up to a whopping 123.5 million by $2040 .^{2}$ Diabetes mellitus
(DM) is the most common medical problem complicating pregnancy and is known to affect pregnancy badly, with estimations projecting $0.3 \%$ of pregnancies to be occurring in women with pre-existing diabetes mellitus. ${ }^{3}$ The prevalence of Gestational Diabetes mellitus (GDM) is increasing, and was approximately $9 \%$ in the period 2007-2010 in the US. ${ }^{3,4}$ Similar prevalence has been reported from other countries. ${ }^{5,6}$ Situation has reportedly been worse in India, with prevalence, along with 
Impaired Glucose Tolerance (IGT), estimated at $16.55 \%$ and $21.6 \% .^{7,8}$ Evidence from the HAPO study reported adverse maternal and perinatal outcomes even in blood glucose levels previously thought safe. ${ }^{9}$ Continued vigilance is hence necessary in order to optimize results. Research assessing multiple variables related to GDM is relatively scarce from our country. The present study aimed at profiling comprehensively all the GDM patients coming to our tertiary care centre, including assessment of incidence, management and perinatal outcome.

\section{METHODS}

In this hospital based prospective observational study carried out at a tertiary care teaching hospital over three years (August 2008- July 2011), the study population consisted of all the pregnant patients attending antenatal clinic at the study centre during study period.

\section{Inclusion criteria}

- All the cases diagnosed as GDM on 50 gm glucose challenge or $100 \mathrm{gm}$ oral glucose tolerance test upon visit to antenatal clinic during study period.

In all, 39 patients were recruited for the study as per mentioned selection criteria. All the patients visiting the antenatal clinic were first screened for the presence or absence of risk factors after taking detailed history. Those with positive history were screened for GDM as early as possible, with rest of the patients screened at 24-28 weeks gestation.

Patients first underwent fasting and postprandial blood sugar level measurement and then accordingly oral glucose challenge and oral glucose tolerance tests were undertaken. If the OGTT results were outside normal limits, with at least two abnormal values in the test, the diagnosis of gestational diabetes (GDM) was noted.

The Carpenter and Coustan criteria was used for the diagnosis of gestational diabetes mellitus cases. ${ }^{10}$ All the diagnosed cases of gestational diabetes mellitus were followed up throughout the course of gestation till delivery.

Variables like pre-eclampsia, polyhydramnios, intra uterine foetal death, intra uterine growth restriction, mode and complications in delivery, birth weight, presence of congenital anomalies, hypoglycaemia, hyperbilirubinemia, still birth or early neonatal death in the babies were recorded.

The management of gestational diabetes was by medical nutrition therapy and/or subcutaneous insulin. Indications for caesarean section were failed induction, breech presentation, foetal distress, large baby and history of 1 or more Caesarean deliveries. Indications for admission to the special care baby unit (SCBU) were prematurity (gestation age- $<37$ weeks), low Apgar score ( $<7$ at 1 minute), low birth weight $(<2.5 \mathrm{~kg})$, presence of congenital anomalies, respiratory distress and birth asphyxia.

Approval from Institutional Ethics Committee was obtained before start of the study. Informed written consent was obtained from each patient before participation in the study.

\section{Statistical analysis}

The data was analysed using SPSS (version 20); by applying chi-square test and ANOVA wherever applicable.

\section{RESULTS}

In this prospective observational study, a total of 39 patients diagnosed as GDM at our tertiary care centre were studied and data analysed. The average age of participants was 29.6 years, with $51.3 \%$ (20) patients above the age of 30 years. $69.3 \%$ (27) of the subjects were multigravida and $30.7 \%$ (12) were primigravida. Majority of women $(56 \%, 22)$ were over $75 \mathrm{~kg}$, with an average weight of $76.8 \mathrm{~kg}$. Analysis of the gestational age at the time of diagnosis showed maximum patients to be diagnosed at the gestational age of 31-35 weeks (n-15) and secondly at 21-25 weeks (n-11). One patient was diagnosed after 35 weeks of period of gestation. (Table $1)$.

Table 1: Gestational age at the time of diagnosis of GDM.

\begin{tabular}{|l|l|l|}
\hline Gestational age in weeks & No. of patients & $\%$ \\
\hline$<20$ weeks & 05 & 12.8 \\
\hline $21-25$ weeks & 11 & 28.2 \\
\hline 26-30 weeks & 07 & 17.9 \\
\hline $31-35$ weeks & 15 & 38.5 \\
\hline$>35$ weeks & 01 & 2.6 \\
\hline Total & 39 & 100.0 \\
\hline
\end{tabular}

A total of $25.6 \%$ of patients had positive family history of diabetes in first or second degree relative. With respect to glycated haemoglobin (HbA1c) levels, 15 patients $(38.4 \%)$ had values between 6-7\% and 14 patients (35.8\%) had levels between $7-8 \%$. Three patients had HBA1c level more than $10 \%$, suggesting very poor control. Two out of these 3 patients had positive family history of GDM. (Figure 1).

While $13 \%$ (5) patients were managed on non-insulin therapy alone which included lifestyle and dietary changes (diabetic diet), $87 \%$ (34) did require insulin along with diabetic diet.

A third (6 out of 18) of the patients who had full term normal vaginal delivery were discharged to be managed on insulin and remaining two third did not require insulin; while only $29 \%$ mothers were off any diabetic 
medication after having a caesarean section. Two were managed on metformin and $62 \%$ of the mothers who had a caesarean section needed insulin.

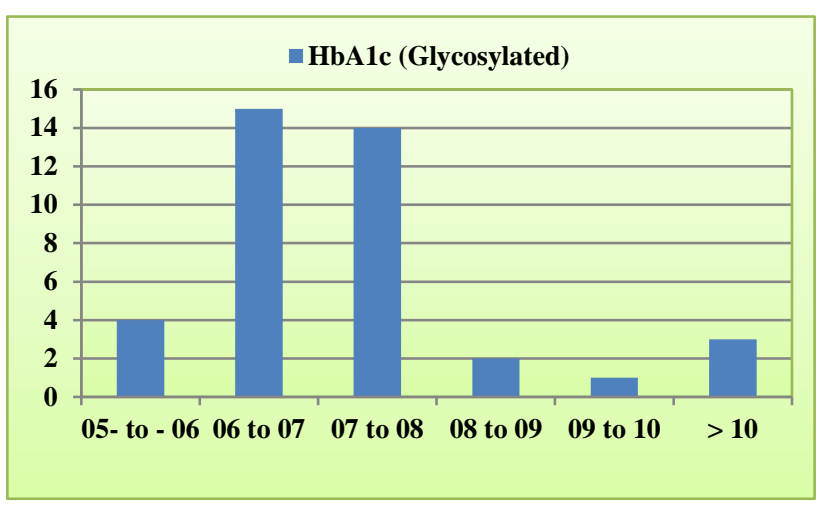

Figure 1: Glycated haemoglobin (HbA1c) levels of participants.

Observations with respect to development of obstetric complications showed 23\% (9) mothers had pregnancy induced hypertension (PIH), 13\% (5) polyhydramnios and $7.6 \%$ (3) had premature rupture of membrane (PROM). Three mothers had babies suffering from intrauterine growth retardation (IUGR) with the birth weights of $1.3 \mathrm{~kg}, 1.8 \mathrm{~kg}$ and $2.0 \mathrm{~kg}$. The $1.3 \mathrm{~kg}$ baby later developed herpes labialis infection (Figure 2).

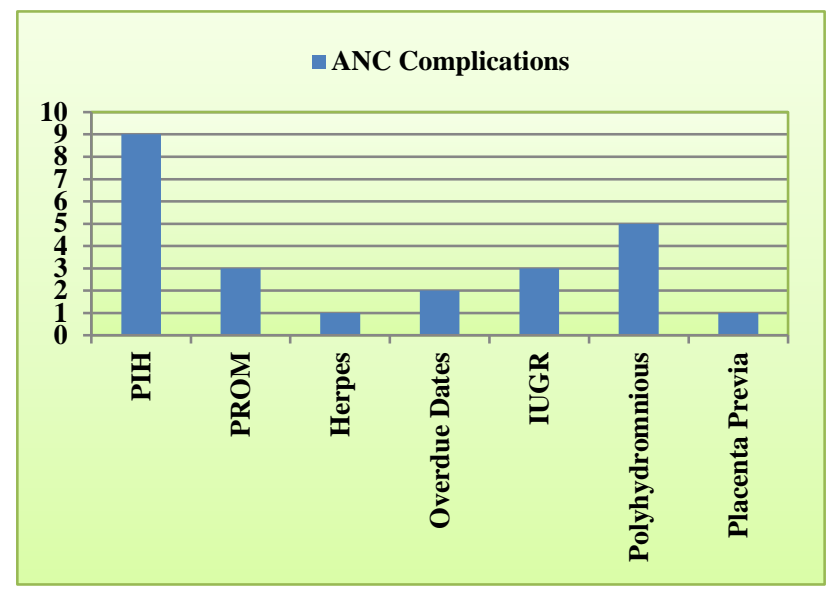

Figure 2: Obstetric complications among study participants.

Sixteen mothers $(41 \%)$ had a full-term normal delivery while $2(5.1 \%)$ patients ended up in preterm labor and delivered normally. Twenty-one mothers (53.84\%) had LSCS, out of which 3 had to have preterm LSCS. Two patients $(5.1 \%)$ went overdue. In majority of cases the indication for caesarean section was foetal distress, meconium stained amniotic fluid, previous LSCS, Cephalo-pelvic disproportion (CPD), premature rupture of membranes (PROM) with non-progress of labour and breech presentation. One patient required emergency LSCS after failure of induction, whereas two had normal vaginal deliveries after induction of labour. Analysis of fetal outcomes showed $34(87.1 \%)$ patients had live births with only 3 still births (7.6\%) and 2 neonatal deaths $(5.1 \%)$. The cause of neonatal death was- in one case-preterm LSCS with severe PIH in an IUGR baby with birth weight $1.3 \mathrm{~kg}$ (LBW), and in other case severe birth asphyxia. Among the three cases of still births one mother was a defaulter who stopped Inj. Insulin on her own and reported in labor with complaints of absent foetal movements. Remaining two cases of still birth were with the same complaints of absent foetal movements which on delivery were found to be macerated. Rest of the babies went home with mother in healthy state. Four out of 39 babies $(10.2 \%)$ had obvious congenital anomalies. Macrosomia is one of the bestknown associations of GDM and the average birth weight was $3.31 \mathrm{~kg}$ and $49 \%$ babies were heavier than $3 \mathrm{~kg}$. Only $3(7.6 \%)$ babies fit the criteria of being truly macrosomic with birth weight above $4 \mathrm{~kg}$.

\section{DISCUSSION}

The present study was aimed at studying the possible interactions of GDM with multiple variables before, during and after pregnancy. Universal screening for GDM is preferred at our hospital to detect more cases and improve maternal and foetal prognosis in comparison to selective screening. The prevalence of GDM in the current study was reported at 1.39 per 1000 delivery over a period of 3 years (39 cases of GDM among 27935 deliveries in 5 years).

Obesity as well as advanced maternal age are important risk factors for GDM and since a higher proportion $(56 \%$ of patients above $75 \mathrm{~kg}$ weight, $\mathrm{n}=22$ ) of our sample population had increased body weight along with GDM, it substantiates the important findings in previous similar studies. ${ }^{11,12}$ In fact, the effect of increased BMI and body weight on the risk of developing GDM is not essentially exclusive of the racial factors. ${ }^{13}$ Indian women have lower BMI in general as compared to Caucasian women, yet they have relatively more abdominal fat deposition (central adiposity).

Maybe, that is the reason that they are at higher risk of developing GDM than the Caucasians. ${ }^{13}$ This is supported by the 'theory of Thin-Fat Indians'- Indians are more insulin resistant in spite of lower BMI; however, for given degree of obesity, Indians have higher adiposity or body fat percentage and higher central obesity than those in other population. ${ }^{14}$ A study was conducted in North India which screened 1436 pregnant women and measured the various outcomes of GDM pregnancies. ${ }^{15} \mathrm{It}$ reported that $72 \%$ of the pregnancies ended up having a LSCS which was much higher than the $54 \%$ in the present study.

It could be related to the more cautious approach at our centre; as the North Indian researchers took liberal approach towards elective caesarean section for the fear of birth trauma. The North Indian study also reported 
higher incidence of polyhydraminos whereas authors observed higher incidence of PIH in present study population. ${ }^{15}$ There are widening range of opinions about the place for universal screening for GDM. Present study showed that the GDM is associated with an increasing morbidity and an adverse outcome for both the mother and the baby. The average gestational age for the diagnosis of GDM in this study was 27.3 weeks. All women were diagnosed after an abnormal fasting blood sugar level which was followed by an OGTT. Screening women with an OGTT is reserved only for women showing certain high-risk characters in most Indian centres. Studies have noted that the high-risk screening method will miss almost $50 \%$ of the diseased. ${ }^{3,4,7}$

Significant improvement was observed in women with bad obstetric history (such as previous still births, abortions, unexplained IUFD) with the current pregnancy after they were treated with GDM management guidelines. It is safe to assume that these women were probably suffering from GDM in the past pregnancies also but remained undiagnosed due to non-screening; as other variables which majorly affect pregnancy outcomes remained largely similar in both the situations. Perhaps, a better screening program would have improved the outcome of their past pregnancies as well. Screening is a unique problem in India, as most of the screening techniques being used internationally aren't affordable or feasible. Fortunately, screening tools that might be more suited to our environment are being developed off late. ${ }^{7}$ An Indian study by V.Balaji et al attempted to validate the recent recommendation by DIPSI for GDM screening and observed that single blood draw 2 hours after oral challenge of $75 \mathrm{~g}$ glucose was an effective screening tool as well as cheaper and feasible. ${ }^{16}$ Another study conducted in China tried to develop a screening technique for smaller centers in the country. ${ }^{17}$ They recommended that doing a single fasting plasma glucose level between 28-32 weeks and making a diagnosis of GDM for women showing a level greater than $5.1 \mathrm{mmol} / \mathrm{L}$ bypassed the need for doing a glucose tolerance test on such women saving costs while still maintaining efficacy in the diagnosis of GDM. ${ }^{17}$

In the present study, maximum patients were diagnosed at the gestational age of 31-35 weeks and secondly at 2125 weeks of period of gestation. So those patients not diagnosed at an early (24-26 weeks) gestational age should not be missed at later weeks; as there is a window to pick up GDM cases later on as well. The plan of management included both diabetic diet and insulin. Insulin has been the standard treatment for gestational diabetes when diet is unsuccessful at normalizing circulating glucose levels. Oral antidiabetic agents are generally considered contraindicated because of the potential for transplacental passage and possible adverse foetal effects. In this study $87 \%$ of patients ultimately required Insulin along with diet for glycaemic control. PIH $(27 \%)$ was observed to be the commonest obstetric complication followed by polyhydromnios (13\%).
Caesarean section rate was $53.8 \%$. In a previously similar study, significantly increased risk of preeclamsia as well as increased rate of caesarean section in abnormal OGTT and impaired glucose tolerance group was observed.18 Neonatal intensive care admission was done for observation for risk of hypoglycaemia for 48 hours. All babies maintained the normal sugar levels with no hypoglycaemic episodes noted. Two neonatal death were observed; one because of severe birth asphyxia and the other because of low birth weight in growth restricted baby in mother having severe PIH. The perinatal mortality rate was observed at $12.6 \%$ in this study. Those babies with congenital anomalies required increased stay in NICU for their respective management, a finding in agreement with the available evidence.

\section{CONCLUSION}

In Conclusion, it can be said that diabetes during pregnancy contributing to a state of hyperglycaemia is a matter of concern and is associated with risk factors as well as high maternal and foetal morbidity. Gestational diabetes mellitus has good maternal and foetal outcomes depending upon how well the blood sugar levels are controlled. Appropriate screening, early detection and necessary intervention will go a long in achieving the same.

Funding: No funding sources

Conflict of interest: None declared

Ethical approval: The study was approved by the Institutional Ethics Committee

\section{REFERENCES}

1. Global Report on Diabetes (2016).World Health Organization (WHO); Available at www.who.int/diabetes/global-report/en/.

2. International Diabetes Federation Atlas, $7^{\text {th }}$ edition (2015); Available at http://www.diabetesatlas.org/resources/2015atlas.html.

3. Ferrara A. Increasing prevalence of gestational diabetes mellitus: a public health perspective. Diabetes Care. 2007;30(2):S141-6.

4. DeSisto CL, Kim SY, Sharma AJ. Prevalence estimates of gestational diabetes mellitus in the US, Pregnancy Risk Assessment Monitoring System (PRAMS), 2007-2010. Prev Chronic Diseases 2014;11:E104.

5. Lamberg S. Prevalence and regional differences of gestational diabetes mellitus and oral glucose tolerance tests in Finland. Eur J Public Health 2012;22(2):278-80.

6. Jenum AK. Impact of ethnicity on gestational diabetes identified with the WHO and the modified International Association of Diabetes and Pregnancy Study Groups criteria. Eur J Endocrinol. 2012;166(2):317-24. 
7. Seshiah V, Balaji V, Balaji MS, Sanjeevi CB, Green A. Gestational Diabetes Mellitus in India. J Assoc Phys India 2004;52:707-11.

8. Swami SR, Mehetre R, Shivane V, Bandgar TR, Menon Ps, Shah NS. Prevalence of carbohydrate intolerance of varying degrees in pregnant females in western India- a hospital-based study. J Indian Med Assoc. 2008;106(11):712-4.

9. Hampton T. Study finds newborn outcomes affected by blood glucose levels during pregnancy. JAMA 2007;298(6):613-4.

10. Carpenter MW, Coustan DR. Criteria for screening tests for gestational diabetes. Am J Obstet Gynecol 1982;144(7):768-73.

11. Joy S, Roman A, Istwan N, Rhea D, Desch C, Stanziano G, Saltzman D. The effect of maternal obesity on pregnancy outcomes of women with gestational diabetes controlled with diet only, glyburide, or insulin. Ame $\mathbf{J}$ Perinatol. 2012;29(08):643-8.

12. Miller HC. The effect of diabetic and prediabetic pregnancies on the fetus and newborn infant. J Pediat. 1946;29:455-61.

13. Retnakaran R, Hanley AJ, Connelly PW, Sermer M, Zinman B. Ethnicity modifies the effect of obesity on insulin resistance in pregnancy: a comparison of
Asian, South Asian, and Caucasian women. J Clin Endocrinol Metab. 2006;91(1):93-7.

14. Yajnik CS, Yudkin JS. The Y-Y paradox. Lancet. 2004;363(9403):163.

15. Tripathi R, Tolia N, Gupta VK, Mala YM, Ramji S. Screening for gestational diabetes mellitus: a prospective study in a tertiary care institution of North India. J Obstet Gynaecol Res. 2012;38(2):3517.

16. Balaji V, Balaji M, Anjalakshi C, Cynthia A, Arthi T, Seshiah V. Diagnosis of gestational diabetes mellitus in Asian-Indian women. Indian J Endocrinol Metab. 2011;15(3):187-90.

17. WEI Yu-mei, YANG Hui-xia. Diagnosis and management of gestational diabetes mellitus in China. Chin Med J.2013;125(7):1206-08.

18. Yariv Y. The association between preeclampsia and the severity of gestational diabetes: The impact of glycemic control. Am J Obstet Gynecol. 2004;191(5):1655-60.

Cite this article as: Gedam S, Ponde S. Study of maternal and fetal outcomes in patients with gestational diabetes mellitus. Int J Reprod Contracept Obstet Gynecol 2019;8:1106-10. 